\title{
DEHIDRASI N-BUTANOL MENJADI SENYAWA BUTENA PADA KATALIS MOLECULAR SIEVE 13 X DALAM REAKTOR UNGGUN TETAP
}

\author{
Melia Laniwati Gunawan, Hendrik Susanto \\ Program Studi Teknik Kimia, \\ Fakultas Teknologi Industri, Institut Teknologi Bandung \\ Jl. Ganesa No. 10 -Bandung- 40132. , \\ E-mail: melia@che.itb.ac.id
}

\begin{abstract}
Abstrak
Salah satu cara untuk mendapatkan senyawa butena tanpa mengandalkan sumber daya tak terbarukan adalah melalui dehidrasi $n$-butanol dengan bantuan katalis asam. Dehidrasi $n$ butanol pada katalis molecular sieve $13 X$ dilakukan di dalam reaktor unggun tetap terbuat dari pipa gelas tegak secara isotermal. Temperatur reaksi divariasikan antara $300-450^{\circ} \mathrm{C}$. Komposisi produk dianalisa menggunakan Gas Chromatograph (GC). Dehidrasi n-butanol ini berorde 1,95 terhadap tekanan parsial $n$-butanol dengan nilai energi aktivasi $89,4 \mathrm{~kJ} / \mathrm{mol}$ dan tetapan Arrhenius 7,99 $\times 10^{6}$. Untuk mempelajari pengaruh parameter operasi (temperatur umpan, laju alir n-butanol, rasio umpan n-butanol terhadap nitrogen, dan diameter partikel katalis) terhadap konversi reaksi, distribusi produk, dan profil temperatur di sepanjang reaktor dilakukan simulasi dalam reaktor unggun tetap non adiabatik non isotermal berdasarkan data percobaan yang telah diperoleh. Model reaktor yang digunakan adalah model heterogen dua dimensi. Nilai koefisien korelasi model yang divalidasi dengan data percobaan menunjukkan harga yang baik yaitu 0,98. Hasil simulasi menunjukkan bahwa peningkatan konsentrasi nbutanol atau temperatur umpan meningkatkan konversi. Peningkatan diameter partikel katalis atau peningkatan laju alir umpan, akan menurunkan konversi reaksi. Reaksi dehidrasi nbutanol menjadi senyawa buten merupakan reaksi yang sedikit eksoterm, oleh karena itu untuk mempertahankan reaksi agar isotermal, temperatur dinding reaktor harus diusahakan tidak melebihi $10^{\circ} \mathrm{C}$ di bawah temperatur umpan.
\end{abstract}

Kata kunci : dehidrasi n-butanol, molecular sieve $13 \mathrm{X}$, simulasi, unggun tetap, kinetik

Abstract

One of the ways of producing butene compounds without relying on non-renewable resources involves the dehydration of $n$-butanol with the aid of acid catalysts. The dehydration of $n$ butanol on molecular sieve $13 X$ catalyst has been undertaken in a fixed bed, vertical glass pipe isothermal reactor. Reaction temperatures were varied between $300-450^{\circ} \mathrm{C}$. Reaction products were analyzed using a Gas Chromatograph (GC). The n-butanol dehydration was observed to have a reaction order of 1.95 with respect to $n$-butanol partial pressure, with an activation energy of $89.4 \mathrm{~kJ} / \mathrm{mol}$ and an Arrhenius constant of $7.99 \times 10^{6}$. To determine the effect of operating parameters (feed temperature, $n$-butanol flowrate, $n$-butanol to nitrogen feed ratio, and catalyst particle diameter), a simulation was undertaken based on the fixed bed, nonadiabatic and non-isothermal reactor model. The reactor model used in the simulation was a 2dimensional heterogeneous reactor. The validated model coefficient of correlation against the experimental data was very good, namely 0.98 . Simulation results indicate that the increase in n-butanol concentration and feed temperature increase the conversion. Increase in catalyst particle diameter and feed flowrate decrease the conversion. The dehydration of $n$-butanol to butene is a mildly exothermic reaction. Therefore, to maintain an isothermal reaction condition, the reactor wall temperature may not exceed $10^{\circ} \mathrm{C}$ below the feed temperature.

Keywords: n-butanol dehydration, molecular sieve $13 \mathrm{X}$, simulation, fixed bed, kinetic 


\section{Pendahuluan}

Senyawa butena merupakan salah satu produk petrokimia yang banyak digunakan untuk berbagai proses kimia. Pada saat ini kebutuhan isomer butena sebagian besar dipenuhi dengan menggunakan bahan baku yang berasal dari sumber daya alam tak terbarukan. Senyawa butanol dapat disintesis melalui proses fermentasi karbohidrat dengan menggunakan bakteri Clostridium Acetobutylicum. Jadi proses sintesis butanol dengan cara ini menggunakan bahan baku dari sumber daya alam yang terbarukan. Salah satu cara untuk mensintesis senyawa butena dari butanol adalah melalui dehidrasi n-butanol pada katalis asam menurut reaksi:

$$
\text { Butanol } \stackrel{\text { Katalis asam }}{\longrightarrow} \text { Butena }+\mathrm{H}_{2} \mathrm{O}
$$

Dengan demikian gabungan proses tersebut di atas merupakan proses pembuatan senyawa butena yang mengandalkan bahan baku berupa sumber daya alam terbarukan. Itu sebabnya jalur proses ini cukup menarik untuk diteliti lebih lanjut.

Penelitian ini bertujuan untuk. mempelajari pengaruh parameter proses (temperatur umpan, rasio n-butanol terhadap nitrogen, laju alir n-butanol, dan diameter partikel katalis) terhadap unjuk kerja reaks dehidrasi n-butanol pada katalis molecular sieve $13 X$ yang diselenggarakan dalam reaktor unggun tetap non adiabatik non isotermal dengan cara simulasi. Untuk simulasi diperlukan persamaan kinetik yang diperoleh dari hasil percobaan di laboratorium.

\section{Fundamental}

Produk dehidrasi n-butanol pada molecular sieve $13 X$ berupa 1-butena, cis-2butena, dan trans-2-butena. Dehidrasi ini diperkirakan mengikuti mekanisme seperti tersaji pada Gambar 1.

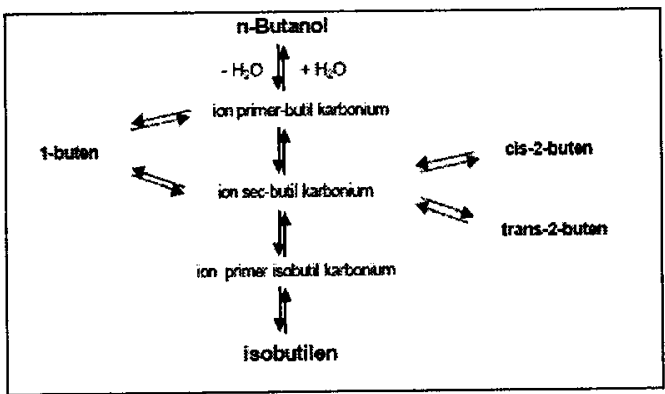

Gambar 1. Mekanisme dehidrasi n-butanol pada katalis asam menjadi senyawa butena

Dari Gambar 1 tampak bahwa dehidrasi n-butanol merupakan reaksi kompleks. Agar dihasilkan produk (senyawa butena) dengan perolehan dan selektivitas yang tinggi perlu dicarikan kondisi operasi dan katalis yang cocok. Jika katalis tidak memiliki kekuatan asam yang cukup, ion primer isobutil karbonium sulit terbentuk, sehingga dalam produk reaksi tidak akan dijumpai isobutena. Kalaupun ada, jumlah isobutena akan sedikit sekali.

Pada penelitian ini katalis yang dipergunakan adalah zeolit $\mathrm{X}$ komesial yang diberi nama dagang molecular sieve $13 \mathrm{X}$. Zeolit $\mathrm{X}$ tergolong mineral faujasite dan berukuran pori $12 \mathrm{MR}$ dengan diameter pori 7,4 $\AA$ dan $6 \mathrm{MR}$ dengan diameter $2,2 \AA$. Struktur kristal zeolit $\mathrm{X}$ adalah face centred cubic (FCC). Zeolit $\mathrm{X}$ mempunyai ratio $\mathrm{Si} / \mathrm{Al}$ yang rendah yaitu antara 1 dan 1,5 . Oleh sebab itu zeolit $X$ umumnya dipergunakan sebagai absorben. Lain halnya dengan zeolit $\mathrm{Y}$ yang berstruktur sama dengan zeolit $\mathrm{X}$, namun mempunyai ratio $\mathrm{Si} / \mathrm{Al}$ yang lebih tinggi, sehingga banyak digunakan sebagai katalis di dalam berbagai reaksi kimia industrial.

Dalam merancang reaktor berskala komersial, mengevaluasi kinerja reaktor, atau memperkirakan umur katalis dibutuhkan persamaan kinetika reaksi kimia dan pengaruh parameter-parameternya Model persamaan kinetik yang paling sederhana adalah persamaan hukum pangkat (Power Law).

$$
-r_{A}=k_{0} \cdot \exp \left(\frac{-E_{a}}{R T}\right) C_{A}^{n}
$$

Menurut Benson W. dkk, seperti dikutip dalam Nurhayati dkk. (1999), dehidrasi alkohol primer pada katalis alumina gel dengan suhu reaksi $200-400^{\circ} \mathrm{C}$ mengikuti persamaan laju reaksi orde pertama dengan pengendali reaksi di permukaan aktif katalis. Lain halnya dengan hasil penelitian Nurhayati dkk yang menemukan bahwa baik n-butanol, buten, maupun molekul air teradsorpsi pada pusat aktif katalis dan sebagai pengendalinya adalah reaksi di permukaan katalis (Nurhayati dkk, 1999). Isomerisasi senyawa-senyawa buten dalam sistem (hasil) dehidrasi n-butanol pada katalis zeolit Y komersial merupakan reaksi orde 1 terhadap masing-masing senyawa buten (Laniwati, 2002).

Secara garis besar, reaktor unggun tetap dapat dibedakan menjadi tiga kategori, yaitu reaktor unggun tetap isotermal, reaktor unggun tetap adiabatik, dan reaktor unggun tetap non adiabatik non isotermal. Model reaktor unggun tetap dapat dibedakan menjadi dua macam, yaitu model pseudohomogen dan model heterogen (Froment and Bischoff, 1990). Model pseudohomogen tidak memperhitungkan 
keberadaan katalis, sedangkan model heterogen memperhitungkan keberadaan katalis, sehingga pada model heterogen terdapat persamaan untuk fluida dan padatan secara terpisah.

Persamaan neraca massa untuk reaktor heterogen dua dimensi adalah

$u_{s} \frac{\partial C_{A}}{\partial z}=\varepsilon D_{e r}\left(\frac{\partial^{2} C_{A}}{\partial r^{2}}+\frac{1}{r} \frac{\partial C_{A}}{\partial r}\right)-\eta \rho_{B} r_{A}$

Sedangkan persamaan neraca energi untuk reaktor heterogen dua dimensi adalah

$$
\begin{aligned}
& u_{s} \rho_{g} C_{p} \frac{\partial T}{\partial t}=\lambda_{r r}\left(\frac{\partial^{2} T}{\partial^{2}}+\frac{1 \partial T}{r \partial}\right)+\eta A_{B}\left(-\Delta I r_{A}+\lambda_{s r}\left(\frac{\partial^{2} T_{s}}{\partial^{2}}+\frac{1}{r} \frac{\partial T_{s}}{\partial r}\right)\right. \\
& h_{f} a_{s}\left(T_{s}^{s}-T\right)=\eta P_{B}(-\Delta H) r_{A}+\lambda_{r} s\left(\frac{\partial^{2} T_{s}}{\partial r^{2}}+\frac{1}{r} \frac{\partial T_{s}}{\partial r}\right)
\end{aligned}
$$

dengan kondisi batas untuk persamaanpersamaan di atas adalah :

Pada $\mathrm{z}=0: \quad \mathrm{C}=\mathrm{Co} ; \quad \mathrm{T}=\mathrm{To} ; \frac{\partial \mathrm{C}}{\partial r}=0$

Pada I $=0$ dan setiap z: $\frac{\partial T}{\partial r}=\frac{\partial T_{s}}{\partial r}=0 ; \frac{\partial C}{\partial r}=0$

Pada $\mathrm{r}=\mathbf{R}$ dan setiap $\mathrm{z}$ :

$$
\begin{gathered}
\alpha_{w}^{f}\left(T_{w}-T\right)=\lambda_{e r} \frac{\partial T}{\partial r} ; \\
\alpha_{v}^{s}\left(T_{w}-T_{s}\right)=\lambda_{v r}{ }^{s} \frac{\partial T_{s}}{\partial r}
\end{gathered}
$$

Persamaan neraca massa dan energi reaktor unggun tetap model heterogen dua dimensi mengandung parameter yang menyatakan sifat fisik campuran reaksi dan sifat transport, yaitu $\rho$ (densitas), $\mu$ (viskositas), $D_{\mathrm{er}}$ (diffusivitas efektif arah radial), $\eta$ (faktor efektivitas), $\quad \mathrm{Cp} \quad$ (kapasitas panas), $\quad \lambda_{\text {er }}$ (konduktivitas termal efektif arah radial), $\alpha_{\mathrm{w}}$ (koefisien perpindahan panas pada dinding), $u_{s}$ (kecepatan superfisial fluida) dan $r_{A}$ (persamaan laju reaksi kimia).

\section{Metodologi}

Percobaan kinetika reaksi dehidrasi nbutanol dilangsungkan di laboratorium Teknik Reaksi Kimia - Teknik Kimia - ITB dengan menggunakan rangkaian peralatan seperti di sajikan oleh Laniwati dkk. (2004). Umpan reaktor berupa n-butanol yang dialirkan ke dalam reaktor menggunakan syringe pump. dengan bantuan gas nitrogen sebagai gas pembawa. Reaksi diselenggarakan secara isotermal pada suhu $350-450{ }^{\circ} \mathrm{C}$. Umpan nbutanol sebelum memasuki reaktor dilewatkan pemanas dahulu sehingga nbutanol berubah fasa menjadi uap dengan temperatur seperti yang diinginkan. Produk reaksi yang berupa gas dianalisis menggunakan kromatografi gas (GC) dengan kolom $0,19 \%$ asam picric/Carbopack $\mathrm{C}$ dan detektor jenis FID ( Flame Ionization Detector). Sedangkan produk cair (merupakan campuran air dan n-butanol sisa) menggunakan GC dengan kolom porapak $P$ dan detektor TCD (Thermal Conductivity Detector)

Model reaktor unggun tetap yang digunakan untuk simulasi dehidrasi n-butanol pada molecular sieve $13 \mathrm{X}$ ini adalah model dua dimensi dengan persamaan neraca massa dan energi telah disajikan di atas. Data-data lainnya dihitung dengan menggunakan beberapa korelasi yang diambil dari ;iteratur. Viskositas campuran gas mengikuti korelasi Wilke (Bird dkk, 1960) Perhitungan difusitas efektif untuk arah radial mengikuti metode yang dikemukakan oleh Froment dan Bischoff (Froment and Bischoff, 1990). Faktor efektifitas dihitung dengan menggunakan persamaan yang diberikan oleh McGreavy dan Cresswell (Froment and Bischoff, 1990). Untuk menghitung kapasitas panas can densitas diasumsikan campuran berupa gas ideal. Konduktivitas termal efektif untuk fasa fluida dihitung dengan menggunakan grafik hubungan konduktivitas termal arah radial terhadap bilangan reynold yang diusulkan oleh Kunii dan Smith (Froment and Bischoff, 1990). Perpindahan panas pada dinding dihitung atas dasar grafik korelasi yang dikemukakan oleh Yagi dan Kunii (Froment and Bischoff, 1990).

Asumsi-asumsi yang digunakan untuk menyelesaikan sistem persamaan dalam simulasi ini yaitu: porositas unggun dianggap seragam di sepanjang reaktor, hilang tekan di sepanjang reaktor dianggap tidak signifikan, sehingga dapat diabaikan, dan fraksi mol sepanjang reaktor untuk menghitung $C p$ dan $D_{e r}$ adalah sama dengan fraksi mol rata-rata. Setelah persamaan kinetik dari percobaan diperoleh dilakukan simulasi untuk mempelajari pengaruh parameter operasi terhadap kinerja reaksi.

Dalam simulasi ini, persamaanpersamaan yang akan diselesaikan melibatkan persamaan differensial parsial. Metode numerik yang digunakan untuk menyelesaikan persamaan differensial parsial tersebut adalah metoda semidiskretisasi. Metode ini hanya mengubah salah satu suku differesial dengan menggunakan penghampiran selisih terhingga yang mengakibatkan persamaan differensial parsial berubah menjadi persamaan differensial biasa. Persamaan differensial biasa ini kemudian diselesaikan dengan bantuan perangkat lunak MATLAB.

Dalam simulasi ini ukuran reaktor yang digunakan berdiameter $20 \mathrm{~cm}$, panjang $1 \mathrm{~m}$, dan porositas unggun 0,57 . Tekanan operasi sekitar $1 \mathrm{~atm}$. Spesifikasi katalis molecular sieve $13 \mathrm{X}$ yang digunakan memiliki densitas bulk 1052,6 $\mathrm{kg} / \mathrm{m} 3$ dan turtuositas $(\tau)$ 2. Parameter yang 
divariasikan dalam simulasi ini adalah temperatur umpan $(623-723 \mathrm{~K})$, rasio mol $\mathrm{N}_{2} /$ n-butanol dalam umpan $(1-3)$, laju alir massa n-butanol (10 -30 kg/jam), dan diameter partikel katalis $(0,2-2 \mathrm{~cm})$.

\section{Hasil dan Analisis}

Berdasarkan pengolahan terhadap data kinetik yang dapat dikumpulkan dan pengujian terhadap persamaan laju reaksi menggunakan model power law (hukum pangkat) diperoleh persamaan laju reaksi konsumsi n-butanol $\left(-r_{A}\right)$ dengan model seperti telah disajikan pada persamaan (1) dengan $\mathrm{A}_{0}=7,99.106, \mathrm{Ea}=$ energi aktivasi $=21,5 \mathrm{kkal} / \mathrm{mol}=89.4 \mathrm{~kJ} / \mathrm{mol}$, dan orde reaksi, $n$, terhadap tekanan parsial $\mathrm{n}$ butanol $($ reaktan $)=1,95$. Produk utama reaksi adalah campuran 1-buten, cis-2-buten, trans-2buten, dan air.

Nilai parameter-parameter di atas memenuhi syarat statistik dan termodinamik. Simpangan hasil estimasi parameter kinetika (antara data percobaan dan model) dengan menggunakan perangkat lunak MATLAB adalah sebesar $1,55 \%$.

Setelah program terbangun, sebelum program dipergunakan untuk simulasi lebih lanjut dilakukan validasi dengan menggunakan data hasil percobaan di laboratorium. Perbandingan antara data laboratorium dengan hasil simulasi disajikan pada Gambar 2. Dari gambar tersebut tampak bahwa data hasil simulasi telah memiliki kecenderungan yang sama dengan data dari percobaan dan memberikan penyimpangan yang sangat kecil. Dengan perkataan lain, ini mengindikasikan bahwa hasil simulasi sudah mempresentasikan sistem yang sebenarnya terjadi di dalam reaktor. Nilai koefisien determinasi $\left(\mathrm{R}^{2}\right)$ yang dihasilkan sebesar 0,986 .

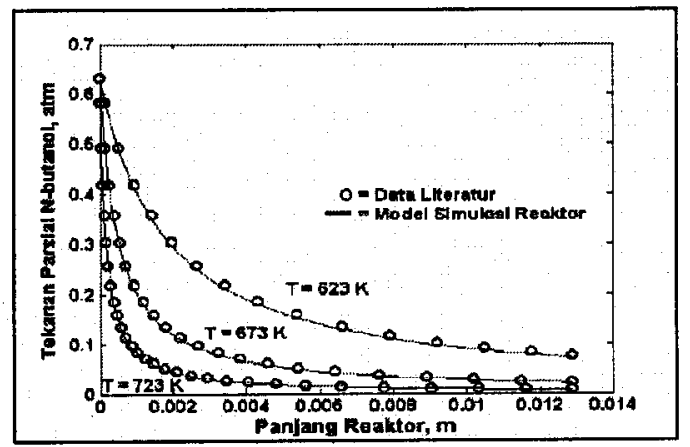

Gambar 2. Perbandingan data hasil percobaan Laniwati (2004) dengan hasil simulasi

Penyimpangan antara data percobaan dengan data hasil simulasi disebabkan oleh adanya perbedaan parameter proses antara saat pengumpulan data percobaan dengan nilai yang digunakan dalam simulasi. Parameter proses tersebut di antaranya adalah porositas unggun dan diameter partikel katalis, yang mana pada saat percobaan keduanya tidak diukur. Atas dasar hasil validasi tersebut, selanjutnya program yang telah dibangun dapat digunakan untuk simulasi sistem reaksi dehidrasi n-butanol menjadi senyawa butena pada katalis molecular sieve $13 \mathrm{X}$ dalam reaktor unggun tetap non adibatik non isotermal.

Dalam simulasi ini, dehidrasi n-butanol dilangsungkan pada kondisi non isothermal non adiabatik. Indikator yang digunakan untuk menunjukkan kinerja reaktor adalah konversi nbutanol dan temperatur reaksi. Hasil simulasi ditampilkan pada Gambar 3 sampai Gambar 7. Gambar 3 memperlihatkan bahwa temperatur umpan sangat mempengaruhi profil konversi nbutanol. Peningkatan . temperatur . umpan

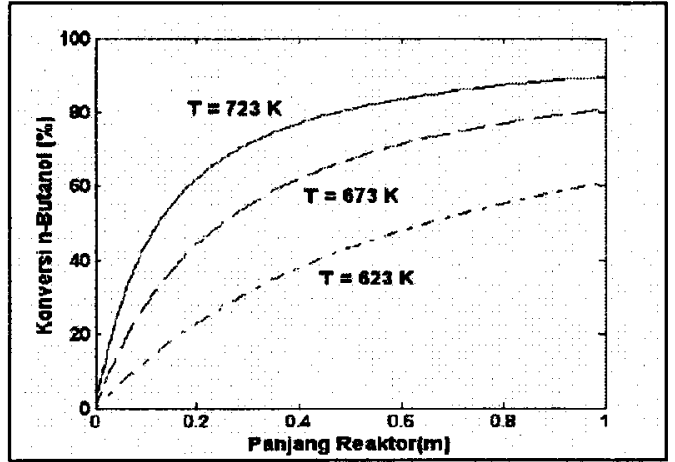

(a)

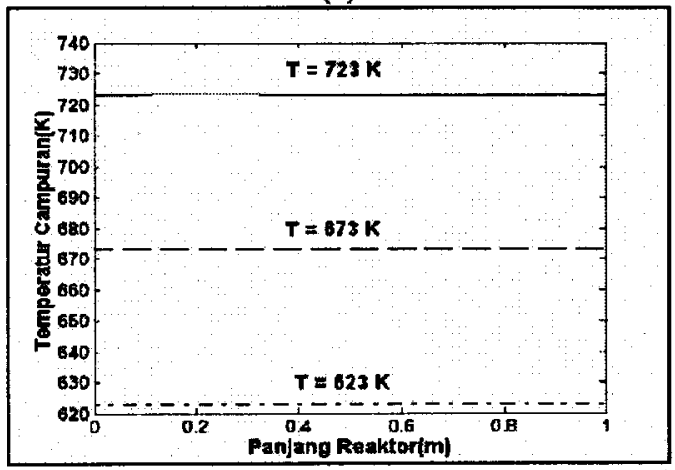

(b)

Gambar 3. Pengaruh temperatur umpan terhadap (a) konversi n-butanol dan (b) temperatur reaksi untuk $\mathrm{N}_{2} / \mathrm{n}$-butanol $=\mathbf{2}$, diameter katalis $1 \mathrm{~cm}$ dan laju alir umpan 30 kg/jam

menyebabkan temperatur reaksipun ikut meningkat, sehingga reaksi berlangsung dengan laju yang lebih tinggi dan konversi reaksi meningkat pula. 
Berdasarkan tinjauan aspek termodinamika, konversi kesetimbangan $\mathrm{n}$ butanol menjadi senyawa 1-butena pada suhu $350-450{ }^{\circ} \mathrm{C}$ adalah $100-78 \%$. Hasil simulasi menunjukkan bahwa sampai panjang reaktor 1 $\mathrm{m}$, reaksi belum mencapai konversi maksimum (kesetimbangan) sehingga jika reaktor diperpanjang sedikit masih memiliki peluang konversi meningkat. Profil temperatur di sepanjang reaktor menunjukkan, bahwa reaksi dehidrasi n-butanol ini merupakan reaksi yang sedikit eksoterm, sehingga panas yang dihasilkan tidak besar, sekalipun konversi reaksinya tinggi.

Salah satu tujuan dalam penelitian ini adalah untuk melihat profil tekanan parsial dan temperatur ke arah radial. Hasil simulasi tidak menunjukkan adanya perubahan yang signifikan. Menurut Tarhan (1983), pengaruh temperatur terhadap dispersi panas dan massa secara radial tidak signifikan untuk reaktor yang dioperasikan secara isotermal. Untuk kasus dehidrasi n-butanol ini, karena kenaikan suhu sangat kecil (Gambar $3 \mathrm{~b}$ ), maka dapat dianggap hampir isotermal, akibatnya profil temperatur arah radial pun tidak berubah secara signifikan.

Gambar 4 memperlihatkan rasio $\mathrm{N}_{2}$ terhadap n-butanol di dalam umpan mempunyai pengaruh yang cukup besar. Persamaan kinetika dehidrasi n-butanol pada katalis molecular sieve $13 \mathrm{X}$ memiliki orde reaksi yang positif dan besar, yaitu 1,95 terhadap tekanan parsial n-butanol, Sehingga semakin tinggi tekanan parsial nbutanol dalam umpan, laju reaksi akan semakin besar yang berakibat konversi akan meningkat pula.

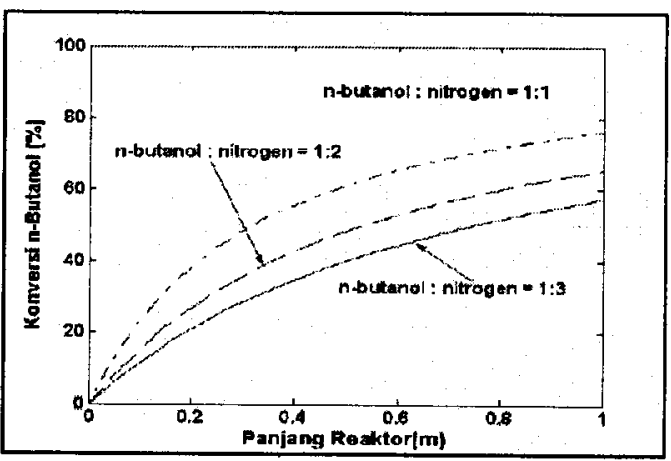

(a)

Gambar 4. Pengaruhi rasio $\mathrm{N}_{2} / \mathrm{n}$-butanol umpan untuk temperatur umpan $623 \mathrm{~K}$ diameter katalis $2 \mathbf{~ m m}$ dan laju alir umpan $30 \mathrm{~kg} / \mathrm{jam}$

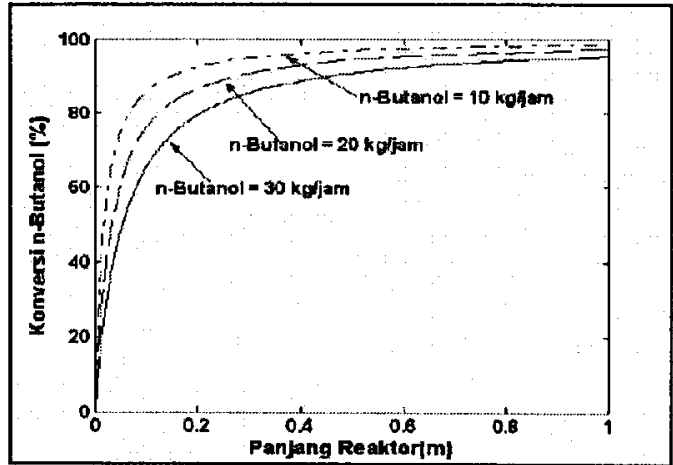

(b)

Gambar 5. Pengaruh laju alir umpan terhadap konversi pada temperatur umpan $723 \mathrm{~K}$, rasio $\mathrm{N}_{2} / \mathrm{n}$-butanol $=2$ dan diameter partikel katalis $2 \mathrm{~mm}$

Gambar 5 memperlihatkan pengaruh variasi laju alir massa umpan n-butanol. Laju alir massa sebanding dengan kecepatan superfisial fluida dalam reaktor, sedangkan dalam persamaan neraca massa reaktor (2) kecepatan superfisial fluida akan membagi suku laju reaksi,akibatnya semakin besar laju alir massa, maka konversi akan menurun. Atau dengan perkataan lain, makin tinggi laju alir umpan, berarti makin singkat waktu tinggal campuran reaksi di dalam reaktor, sehingga konversinyapun rendah.

Gambar 6 memperlihatkan bahwa diameter partikel katalis sangat berpengaruh terhadap konversi reaksi. Semakin besar diameter partikel katalis, konversi reaksi semakin menurun. Hal ini disebabkan karena diameter partikel katalis sangat berpengaruh terhadap parameter transport yaitu faktor effektivitas. Faktor effektivitas merupakan parameter kinetika yang menyatakan perbandingan laju reaksi berkatalis yang bereaksi pada permukaan dengan laju reaksi yang bereaksi pada permukaan dan pori katalis. Diameter partikel katalis sebanding dengan jarijari partikel katalis, sedangkan jari-jari partikel katalis berbanding terbalik dengan faktor effektivitas. Semakin besar diameter partikel katalis, mengakibatkan effektivitas akan semakin menurun. Semakin besar diameter partikel katalis menyebabkan adanya pusat aktif katalis yang berada jauh dari permukaan luar katalis, sehingga sulit bagi reaktan untuk masuk mencapai daerah pusat aktif tersebut yang berada jauh dari permukaan katalis. Faktor effektivitas ini merupakan salah satu parameter yang terdapat di dalam persamaan neraca massa reaktor unggun tetap. Semakin besar faktor effektivitas, maka laju reaksi akan semakin besar. 


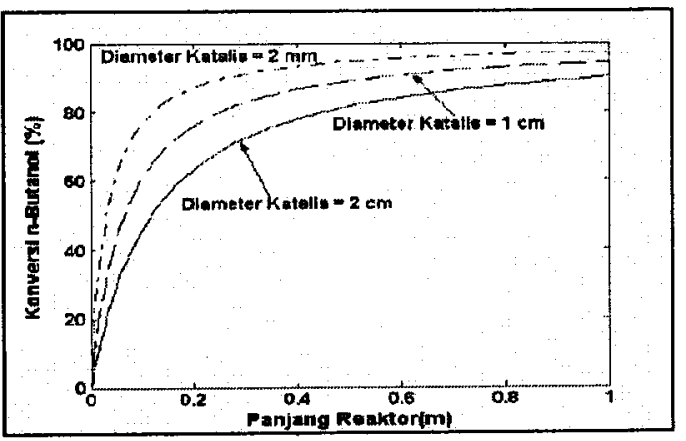

Gambar 6. Pengaruh diameter partikel katalis terhadap konversi pada temperatur umpan $723 \mathrm{~K}$, rasio $\mathrm{N}_{2} / \mathrm{n}$-butanol $=1$ dan laju alir massa $30 \mathrm{~kg} / \mathrm{jam}$

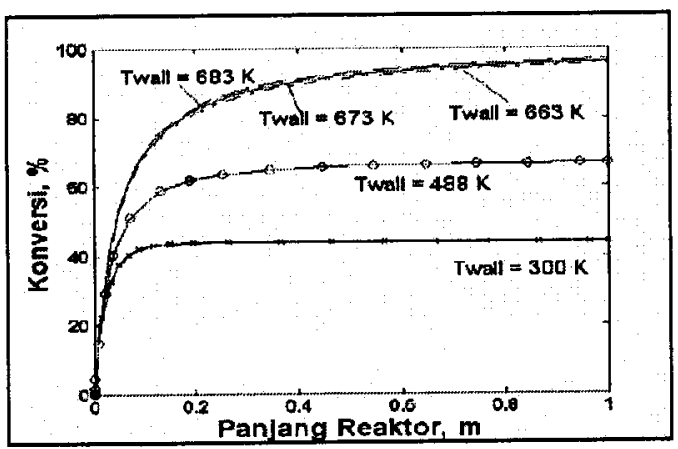

(a)

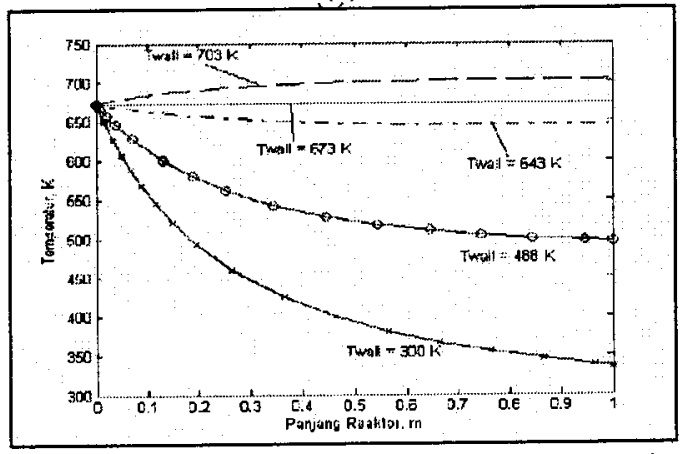

(b)

Gambar 7. Pengaruh temperatur dinding reaktor terhadap (a) konversi dan (b) temperatur reaksi , untuk temperatur umpan $673 \mathrm{~K}$, laju alir massa $10 \mathrm{~kg} / \mathrm{jam}$, rasio $\mathrm{N}_{2} / \mathrm{n}$-butanol $=1$, dan diameter partikel katalis $=\mathbf{2} \mathbf{~ m m}$

Gambar 7 memperlihatkan pengaruh temperatur dinding terhadap kinerja reaktor, yang diwakili oleh konversi. Terlihat bahwa dinding dengan temperatur lebih tinggi dari temperatur umpan dapat meningkatkan konversi, demikian pula sebaliknya. Temperatur dinding yang berfluktuasi dengan rentang cukup besar dapat mengganggu kinerja reaktor. Bila dinding reaktor dikontakkan langsung dengan suhu lingkungan, maka panas reaksi yang dihasilkan (reaksi sedikit eksoterm) tidak dapat mengimbangi panas yang hilang ke lingkungan, akibatnya temperatur operasi dalam reaktor (Gambar 7 (b)) turun drastis dan reaksi berhenti pada konversi yang rendah. Dengan demikian untuk mempertahankan kondisi reaksi, fluktuasi temperatur dinding sebaiknya tidak melebihi $10^{\circ} \mathrm{C}$ di bawah temperatur umpan. Untuk itu dinding reaktor perlu dilengkapi dengan media penukar pemanas atau diinsulasi dengan baik untuk mencegah hilangnya panas ke lingkungan dalam jumlah besar.

Komposisi produk reaksi tidak/belum dapat diprediksi melalui simulasi ini, karena model persamaan kinetik yang dipilih tidak dipengaruhi oleh konsentrasi atau tekanan parsial produk, dalam hal ini senyawa-senyawa buten dan air. Agar komposisi senyawa senyawa butena sepanjang reaktor dapat diperkirakan, sebaiknya model persaman kinetik dehidrasi n-butanol ini bukan bentuk hukum pangkat, tetapi model persamaan kinetik untuk reaksi berkatalis heterogen.

\section{Kesimpulan}

Untuk rentang suhu $350-450^{\circ} \mathrm{C}(623$ -

$723 \mathrm{~K}$ ) seiring dengan peningkatan suhu umpan, konversi juga meningkat. Semakin besar laju alir massa umpan, maka konversi semakin rendah. Semakin besar rasio nitrogen terhadap n-butanol dalam umpan atau semakin besar partikel katalis akan menghasilkan konversi $\mathrm{n}$ butanol semakin rendah. Dehidrasi n-butanol menjadi butena merupakan reaksi yang sedikit eksoterm. Dalam pengoperasiannya, reaktor perlu menggunakan insulasi yang baik atau dilengkapi dengan media pemanas. Hasil simulasi juga menunjukkan tidak adanya gradien temperatur konversi ke arah radial.

\section{Ucapan Terima Kasih}

Ucapan terima kasih secara khusus ditujukan kepada Bambang Yudistira dan Hendrick yang telah membantu pelaksanaan percobaan di laboratorium. 


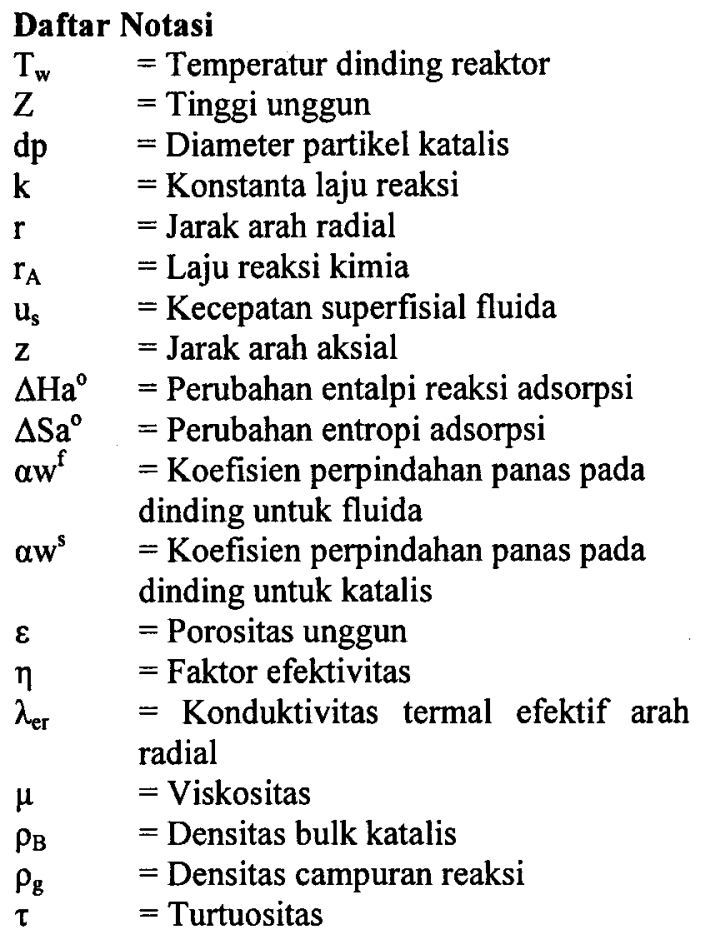

\section{Daftar Pustaka}

[1] Bird, R.B., et.al., (1960), "Trasport Phenomena", John Wiley and Sons, hal 1925.
[2] Chapra, S.C., and Canale, R.P., (1998), "Numerical Methods for Engineers with Programming and Software Aplication," 3rd edition, McGraw-Hill Inc, Singapore.

[3] Froment, G.F., and Bischoff, K.B., (1990), "Chemical Reactor Analysis and Design", 2nd edition, John Wiley and Sons.

[4] Laniwati, M., Subagjo, Soerawidjaja, T.H., dan Sudarno, (2004), "Kinetika Isomerisasi Senyawa buten dala Sistem Dehidrasi nButanol pada Katalis Zeolit-Y Komersial", Prosiding Seminar Teknik Kimia Soehadi Reksowardojo, Teknik Kimia- ITB, Bandung,

[5] Laniwati, M., Ardi, R., dan Antoni, (2002), "Simulasi Reakstor unggun tetap untuk penyelenggaraan reaksi Dedidrasi n-butanol pada katalis alumina aktif ", Prosiding Seminar Teknik Kimia Soehadi Reksowardojo, Jurusan Teknik Kimia- ITB, Bandung

[6] Nurhayati, Laniwati, M., dan Subagjo, (1999), "Kinetika Dehidrasi n-Butanol pada Katalis Alumina Aktif', Prosiding Seminar Nasional Proses dan Rekayasa Kimia, UNDIP- Semarang, E-19-1 - E-19-6

[7] Tarhan, M.O., (1983), "Catalytic Reactor Design”, McGraw-Hill Inc. 